\title{
Association between Elder Abuse and Metabolic Syndromes: Findings from the Chicago Health and Aging Project
}

\author{
XinQi Donga ${ }^{\mathrm{a}}$ Melissa Simon ${ }^{\mathrm{b}}$ \\ ${ }^{a}$ Rush Institute for Healthy Aging, Rush University Medical Center and ${ }^{b}$ Department of Internal Medicine, \\ Northwestern University, Chicago, III., USA
}

\section{Key Words}

Elder abuse - Metabolic syndromes .

Population-based study

\begin{abstract}
Background: Elder abuse and metabolic syndromes are both important public health issues and are associated with increased morbidity and mortality. This study aimed to examine the associations between elder abuse and risk for metabolic syndromes. Methods: The Chicago Health and Aging Project (CHAP) cohort is a population-based study $(n=4,586)$. We identified 676 participants with some form of elder abuse reported to a social services agency. The primary independent variable was elder abuse reported to a social services agency. Outcomes were metabolic syndrome as categorized by World Health Organization (WHO), American Heart Association (AHA) and International Diabetes Federation (IDF) criteria. Bivariate and logistic regression analyses were used to assess the association between elder abuse and different definitions of metabolic syndromes. Results: In the bivariate analyses, elder abuse victims were more likely than those without elder abuse to have metabolic syndromes [22.4 vs. $10.7 \%$ (WHO), 50.7 vs. $40.0 \%$ (AHA) and 47.7 vs. $33.5 \%$ (IDF)]. After adjusting for potential confounding factors, elder abuse was associated with an increased risk for metabolic syndromes according to WHO [OR, 3.95 (2.86-
\end{abstract}

5.47)], AHA [OR, 2.03 (1.56-2.64)] and IDF [OR, 2.55 (1.973.29)] criteria. Interaction term analyses indicate that the association between elder abuse and metabolic syndromes may be moderated by sociodemographic characteristics but not by health-related or psychosocial factors. Conclusion: Elder abuse is associated with an increased risk for metabolic syndromes. Research is needed to examine the association between elder abuse and cardiovascular disease.

(c) 2014 S. Karger AG, Basel

\section{Introduction}

Elder abuse is an important public health issue and affects millions of US elderly persons each year, with recent data indicating that 1 out of 10 older adults have experienced some forms of elder abuse $[1,2]$. While there are limited research and policy dealing with issues of elder abuse, adult protective services (APS) is the main agency dealing with the report and investigation of elder abuse [physical, psychological and sexual abuse, neglect (caregiver neglect and self-neglect) and financial exploitation] in order to protect this vulnerable population. At the same time, recent studies suggest that elder abuse reported to APS is associated with an increased risk of morbidity and mortality [3-5]. These studies suggest that consequences of elder abuse are particularly high among those

\section{KARGER 125}

(c) 2014 S. Karger AG, Basel

0304-324X/14/0615-0389\$39.50/0

E-Mail karger@karger.com

www.karger.com/ger
XinQi Dong, MD, MPH

Rush Institute for Healthy Aging, Rush University Medical Center

1645 West Jackson, Suite 675

Chicago, IL 60612 (USA)

E-Mail xinqi_dong@rush.edu 
who are most vulnerable, especially those with lower levels of cognitive function and physical function and higher levels of psychological distress and social isolation [4, 5]. Furthermore, evidence suggests that elder abuse may be associated with cardiovascular-related mortality [4]. However, our current understanding of elder abuse comes almost exclusively from survey research methods and our translational understanding of physiological abnormalities associated with elder abuse in the general population remains limited. This knowledge is critical to understanding multi-level associations and potential mechanisms between elder abuse and its adverse health and physiological outcomes.

Metabolic syndrome is described as a disorder in energy utilization and storage diagnosed by co-occurrences of specific medical conditions and physiological parameters. Metabolic syndrome increases the risk of developing cardiovascular disease and is associated with significant morbidity and mortality [6-8]. However, there are variations in the definitions of metabolic syndromes, including, but not limited to, those of the World Health Organization (WHO), American Heart Association (AHA) and International Diabetes Federation (IDF) [9-11]. To our knowledge, we are not aware of any epidemiological study that has examined the associations between elder abuse and metabolic syndrome in community-dwelling populations. Improved understanding of these relationships could help to inform research, practice and policy at the national level.

In this report, we examine the association between elder abuse and different definitions of metabolic syndromes using WHO, AHA and IDF criteria, within the context of a population-based cohort study. Especially, prior literature suggests that elder abuse and metabolic syndromes have many shared risk factors in community populations. In this article, we hypothesize that elder abuse is independently associated with an increased risk for metabolic syndromes after controlling for potential confounding factors.

\section{Methods}

\section{Design and Participants}

The study population consisted of participants in the Chicago Health and Aging Project (CHAP) $[12,13]$. Briefly, the study enrolled residents aged 65 years and older in four adjacent neighborhoods in Chicago. Data collection included an in-person interview conducted in participants' homes, with standardized questionnaires and anthropometric measurements. Blood was collected in- home and sent to Quest laboratory for cholesterol level testing. Written informed consent was obtained and the study was approved by the Institutional Review Board.

\section{Elder Abuse}

Reports of elder abuse to social services agencies came from a variety of sources. The definition of abuse included physical abuse, sexual abuse, psychological abuse, neglect (caregiver and self-neglect) and financial exploitation [14]. Physical abuse is defined as inflicting physical pain or injury upon an older adult. Sexual abuse is touching, fondling, intercourse, or any other sexual activity with an older adult, when the older adult is unable to understand, unwilling to consent, threatened or physically forced. Psychological abuse involves verbal assaults, threat of abuse, harassment or intimidation. Caregiver neglect is a caregiver's failure to provide an older adult with life's necessities, including, but not limited to, food, clothing, shelter or medical care. Self-neglect is assessed by the domains of personal hygiene and grooming, household and environmental hazards, health needs and overall home safety concerns. Financial exploitation includes the misuse or withholding of an older adult's resources by another, to the disadvantage of the elderly person or to the profit or advantage of someone else. This resulted in a total of 676 older CHAP participants who had some form of elder abuse reported at APS.

\section{Assessment of Metabolic Syndromes}

In order to fully delineate the relationship between elder abuse and metabolic syndromes, we use three different definitions according to criteria by the WHO, AHA and IDF. Cholesterol level testing included total cholesterol ( $\mathrm{mg} / \mathrm{dl})$, low-density lipoprotein (LDL; mg/dl), high-density lipoprotein (HDL; mg/dl), low levels of HDL ( $<50$ in women and $<40$ in men) and triglyceride $(\mathrm{mg} / \mathrm{dl})$. Blood pressure was ascertained by trained research assistants using standard techniques at participants' homes to measure both systolic blood pressure (SBP) and diastolic blood pressure (DBP) in a sitting position. Medical histories, including diabetes mellitus, were self-reported by participants. Body mass index (BMI) was measured using weight $(\mathrm{kg})$ divided by height (meter) squared. Medication was recorded from participants' homes and categorized by two separate clinicians into specific classes of indications.

According to the WHO, metabolic syndrome is defined as a history of diabetes mellitus and two of the following: (a) SBP $\geq 140 \mathrm{~mm}$ $\mathrm{Hg}$ or DBP $\geq 90 \mathrm{~mm} \mathrm{Hg}$; (b) triglyceride $\geq 150 \mathrm{mg} / \mathrm{dl}$ and $\mathrm{HDL}<50$ $\mathrm{mg} / \mathrm{dl}$ in women or HDL $<40 \mathrm{mg} / \mathrm{dl}$ in men or (c) BMI $>30$. According to the AHA, metabolic syndrome is defined as three of the following: (a) BMI $>30$; (b) triglyceride $\geq 150 \mathrm{mg} / \mathrm{dl}$; (c) $\mathrm{HDL}<50$ $\mathrm{mg} / \mathrm{dl}$ in women or HDL $<40 \mathrm{mg} / \mathrm{dl}$ in men; (d) SBP $\geq 130 \mathrm{~mm} \mathrm{Hg}$ or DBP $\geq 85 \mathrm{~mm} \mathrm{Hg}$ or on any antihypertensive medications or (e) history of diabetes mellitus. According to the IDF, metabolic syndrome is defined as having a BMI $>30$ and two of the following: (a) triglyceride $>150 \mathrm{mg} / \mathrm{dl}$ or taking either fenofibrate or gemfibrozil specifically for increased triglyceride levels; (b) low HDL ( $<50 \mathrm{mg}$ / $\mathrm{dl}$ in women and $<40 \mathrm{mg} / \mathrm{dl}$ in men) or taking any statins for high cholesterol; (c) SBP $>130 \mathrm{~mm} \mathrm{Hg}$ or DBP $>85 \mathrm{~mm} \mathrm{Hg}$ or on any antihypertensive medications or (d) history of diabetes mellitus.

\section{Other Relevant Factors}

Demographic variables were assessed prior to the report of elder abuse and included age (in years), sex (male or female), race (self-reported: non-Hispanic black vs. non-Hispanic white) and 
income categories $(1=0-4,999$ USD; $2=5,000-9,999$ USD; $3=$ 10,000-14,999 USD; $4=15,000-19,999$ USD; $5=20,000-24,999$ USD; $6=25,000-29,999$ USD; $7=30,000-34,999$ USD; $8=35,000$ 49,999 USD; $9=50,000-74,999$ USD and $10=75,000$ USD and over). Self-reported medical conditions included a number of common conditions: hypertension, diabetes mellitus, stroke, coronary artery disease, hip fracture and cancer. Cigarette smoking (ever smoked) and alcohol use (more than 12 drinks in the last 12 months) were assessed based on a series of questions derived from the Established Populations for Epidemiological Studies of the Elderly (EPESE) project [15].

Cognitive and physical function has been associated with increased risk for elder abuse $[16,17]$. Cognitive assessments in the CHAP included the Mini-Mental State Examination [18], the East Boston Memory Test [19] and the Symbol Digit Modalities Test [20]. In order to minimize floor and ceiling effects, a z-scored global cognitive function measure was constructed to examine overall cognitive function. Physical function was assessed by direct performance testing, which provides a more objective and detailed assessment of certain abilities (range 0-15) [21] than self-report. It assesses walking speed, tandem stand ability and repeated chair stand ability. Associations between measures of reported disability and physical performance tests are usually strong [22].

Psychosocial factors included assessment of depressive symptoms and social network. Symptoms of depression were measured using a modified version [23] of the Center for Epidemiologic Studies of Depression Scale (CES-D) [24]. Social network was summarized as the total number of children, relatives and friends seen at least monthly [15]. Social engagement refers to the frequency of activities older adults participate in outside of their house, such as church activities, arts and leisure activities and community activities.

\section{Analytic Approach}

Descriptive analyses were conducted by elder abuse status across all variables for metabolic syndromes using WHO, AHA and IDF criteria: diabetes mellitus, SBP, DBP, triglyceride, HDL and BMI. The prevalence of metabolic syndromes was calculated and presented by age groups and gender. Bivariate analyses were conducted to compare elder abuse and metabolic syndrome using $\chi^{2}$ with corresponding degree of freedom and $p$ values. Then, we calculated the prevalence of metabolic syndromes for elder abuse status across age groups and gender. Moreover, we used logistic regression models to examine the association between elder abuse and metabolic syndrome definitions and specific items adjusting for age and sex.

Furthermore, we considered a series of logistic regression models to examine potential independent associations between elder abuse and metabolic syndromes. In model A, we considered sociodemographic and socioeconomic factors. In model B, we added to the prior model by including health-related factors of medical comorbidities, comprehensive measures of global cognitive function and directly observed physical performance testing. In model $\mathrm{C}$, we added psychological and social variables of depressive symptoms, social network and social engagement. In model D, we added the health behavior factors of smoking and alcohol consumption to the prior model.

Lastly, we considered interaction term analyses for all the above factors with respect to the relationship between elder abuse and different metabolic syndromes. Interaction terms (e.g. elder

Elder Abuse and Metabolic Syndromes abuse $\times$ age, elder abuse $\times$ sex, elder abuse $\times$ depressive symptoms, etc.) considered all potential factors of age, sex, race, education, income, medical conditions, global cognitive function, directly observed physical performance testing, depressive symptoms, social networks, social engagement, smoking and alcohol use. Parameter estimates (PE), standard errors (SE), odds ratios (OR), 95\% confidence intervals $(\mathrm{CI})$ and corresponding $\mathrm{p}$ values were reported for the regression analyses. All analyses were carried out using $\mathrm{SAS}^{\circledR}$, version 9 (SAS Institute Inc., Cary, N.C., USA) [25].

\section{Results}

\section{Elder Abuse and Metabolic Syndromes}

In the descriptive analyses (table 1), compared with those study participants without elder abuse, those with elder abuse reported to APS had a greater proportion of metabolic syndromes across all three criteria. According to WHO criteria, the prevalence of metabolic syndrome was $22.4 \%$ for those with elder abuse and $10.7 \%$ for those without elder abuse. According to AHA criteria, the prevalence of metabolic syndrome was $50.7 \%$ for those with elder abuse and $40.0 \%$ for those without elder abuse. According to IDF criteria, the prevalence of metabolic syndrome was $47.7 \%$ for those with elder abuse and $33.5 \%$ for those without elder abuse.

\section{Prevalence of Metabolic Syndromes by Age, Sex and BMI}

The prevalence of metabolic syndrome varied greatly by age and sex, especially among the younger age groups (table 2). For example, among women 65-70 years of age, the prevalence of metabolic syndrome per WHO criteria was $53.9 \%$ for those with elder abuse and $13.2 \%$ for those without elder abuse. Among men 65-70 years of age, the prevalence of metabolic syndrome was $42.9 \%$ for those with elder abuse and $17.2 \%$ for those without elder abuse. Similar trends were found using other metabolic syndrome definitions. Interestingly, prevalence differences in metabolic syndrome among younger age groups were significantly higher for elder abuse victims according to all three criteria.

\section{Specific Criteria Items of Metabolic Syndrome \\ Definitions}

Table 3 examines specific criteria items from the metabolic syndrome definitions. Our data indicate that those with elder abuse were more likely to have metabolic syndromes after adjusting for age and sex. According to WHO criteria items, those with elder abuse were more likely to have a history of diabetes mellitus (PE, 0.40; SE, 
Table 1. Characteristics of elder abuse and metabolic syndrome definitions

\begin{tabular}{lcrlr}
$\begin{array}{l}\text { Elder abuse: } \\
\text { no }\end{array}$ & $\begin{array}{l}\text { Elder abuse: } \\
\text { yes }\end{array}$ & \multicolumn{2}{l}{ d.f. $\mathrm{p}$} \\
\hline 3,721 & 612 & & & \\
$398(10.70)$ & $137(22.39)$ & 66.36 & 1 & $<0.001$ \\
$2,093(24.19)$ & $602(31.47)$ & 43.74 & 1 & $<0.001$ \\
$3,141(39.12)$ & $774(42.67)$ & 7.77 & 1 & 0.005 \\
$618(16.68)$ & $93(16.52)$ & 0.01 & 1 & 0.922 \\
$1,938(24.72)$ & $493(28.95)$ & 13.18 & 1 & $<0.001$ \\
3,910 & 676 & & & \\
$1,565(40.03)$ & $343(50.74)$ & 27.23 & 1 & $<0.001$ \\
$1,938(24.72)$ & $493(28.95)$ & 13.18 & 1 & $<0.001$ \\
$1,238(33.42)$ & $171(30.37)$ & 2.06 & 1 & 0.152 \\
$1,141(30.80)$ & $198(35.17)$ & 4.34 & 1 & 0.037 \\
$7,396(88.19)$ & $1,670(89.11)$ & 1.26 & 1 & 0.262 \\
$2,093(24.19)$ & $602(31.47)$ & 43.74 & 1 & $<0.001$ \\
3,852 & 673 & & & \\
$1,291(33.52)$ & $321(47.70)$ & 50.24 & 1 & $<0.001$ \\
$1,938(24.72)$ & $493(28.95)$ & 13.18 & 1 & $<0.001$ \\
$1,353(38.13)$ & $192(34.91)$ & 2.11 & 1 & 0.147 \\
$3,343(72.52)$ & $547(69.42)$ & 3.21 & 1 & 0.073 \\
$7,396(88.19)$ & $1,670(89.11)$ & 1.26 & 1 & 0.262 \\
$2,093(24.19)$ & $602(31.47)$ & 43.74 & 1 & $<0.001$ \\
\hline
\end{tabular}

WHO definition (eligible participants: $\mathrm{n}=4,333$ )

MS according to the WHO: history of DM and two of the following (a-c)

History of DM

(a) SBP $\geq 140$ or DBP $\geq 90$

(b) Triglyceride $\geq 150$ and HDL $<50$ in women or HDL $<40$ in men

(c) BMI $>30$

AHA definition (eligible participants: $\mathrm{n}=4,586$ )

MS according to the AHA: three of the following (a-e)

(a) BMI $>30$

(b) Triglyceride $\geq 150$

(c) Low HDL (HDL $<50$ in women and HDL $<40$ in men)

(d) SBP $\geq 130$ or DBP $\geq 85$ or on any antihypertensive medications

(e) History of DM

IDF definition (eligible participants: $\mathrm{n}=4,525$ )

MS according to the IDF: BMI $>30$ and two of the following $(\mathrm{a}-\mathrm{d})$

History of BMI $>30$

(a) Triglyceride $>150$ or taking either fenofibrate or gemfibrozil

(b) Low HDL ( $\mathrm{HDL}<50$ in women and HDL $<40$ in men) or on any statins

(c) SBP $>130$ or DBP $>85$ or on any antihypertensive medications

(d) History of DM

Values are $\mathrm{n}$ or $\mathrm{n}(\%)$. Units for SBP and DBP are $\mathrm{mm} \mathrm{Hg}$ and for triglyceride and HDL they are $\mathrm{mg} / \mathrm{dl}$. MS = Metabolic syndrome; $\mathrm{DM}=$ diabetes mellitus.

Table 2. Prevalence of metabolic syndromes by elder abuse and metabolic syndromes by age, sex and BMI

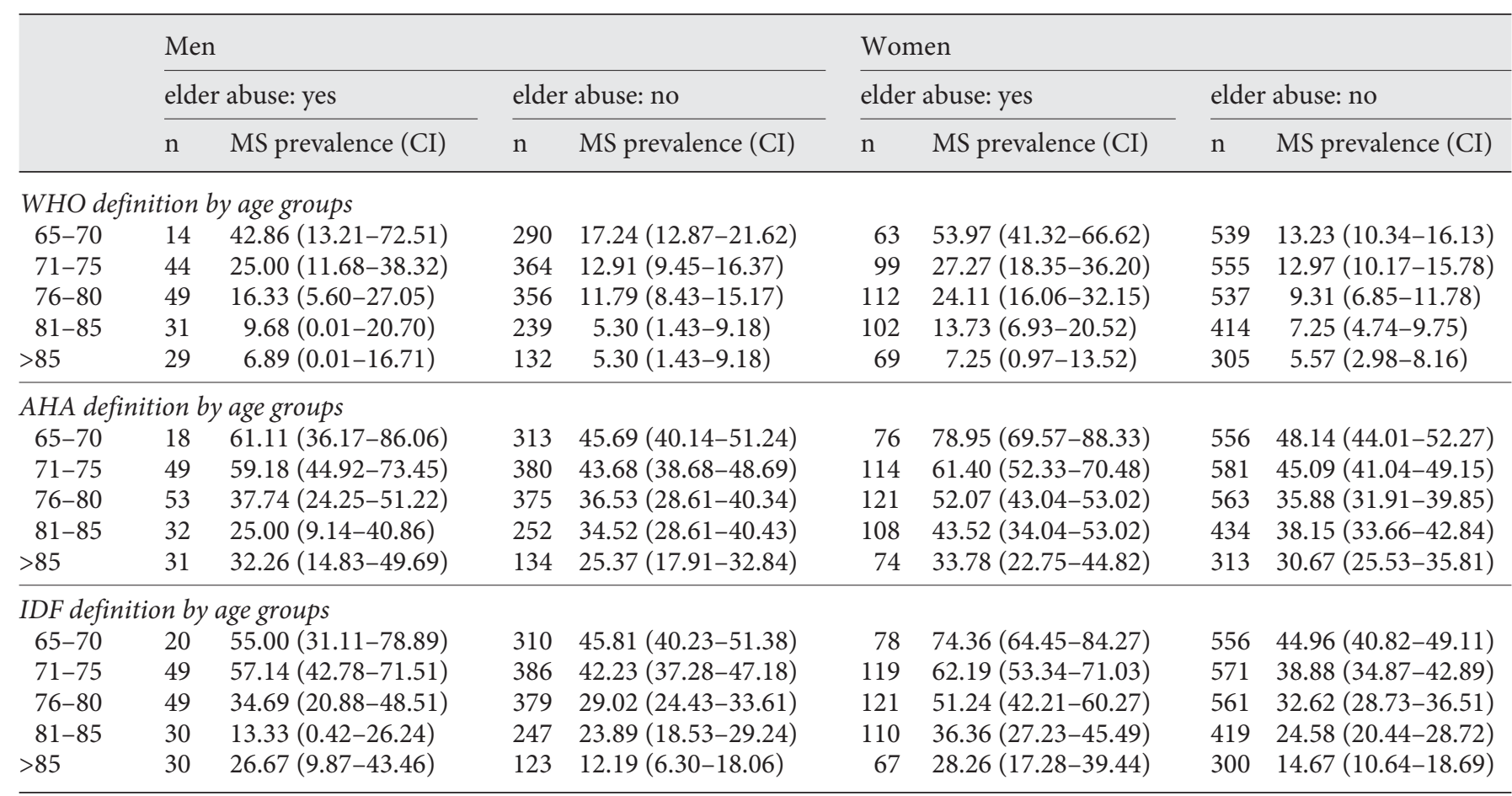

MS = Metabolic syndrome 
Table 3. Age- and sex-adjusted associations between elder abuse and different definitions of metabolic syndromes

\begin{tabular}{|c|c|c|c|c|c|c|c|}
\hline & \multicolumn{2}{|l|}{ Age } & \multicolumn{2}{|l|}{ Sex } & \multicolumn{3}{|l|}{ Elder abuse } \\
\hline & $\mathrm{PE}, \mathrm{SE}$ & OR (95\% CI) & $\mathrm{PE}, \mathrm{SE}$ & OR $(95 \% \mathrm{CI})$ & $\mathrm{PE}, \mathrm{SE}$ & OR (95\% CI) & $\mathrm{p}$ value \\
\hline WHO & $-0.08,0.01$ & $0.91(0.89-0.92)$ & $0.03,0.09$ & $1.04(0.85-1.26)$ & $1.76,0.15$ & $5.82(4.34-7.79)$ & $<0.001$ \\
\hline History of DM & $-0.08,0.01$ & $0.91(0.89-0.92)$ & $0.14,0.05$ & $1.15(1.06-1.26)$ & $0.40,0.06$ & $1.49(1.34-1.67)$ & $<0.001$ \\
\hline $\mathrm{SBP} \geq 140$ or $\mathrm{DBP} \geq 90$ & $-0.08,0.01$ & $0.91(0.89-0.92)$ & $0.01,0.04$ & $1.01(0.93-1.10)$ & $0.18,0.05$ & $1.20(1.08-1.34)$ & $<0.001$ \\
\hline \multicolumn{8}{|l|}{ Triglyceride $\geq 150$ and $\mathrm{HDL}<50$ in } \\
\hline $\mathrm{BMI}>30$ & $-0.08,0.01$ & $0.91(0.89-0.92)$ & $-0.37,0.05$ & $0.69(0.63-0.76)$ & $0.19,0.06$ & $1.21(1.07-1.37)$ & 0.003 \\
\hline AHA & $-0.08,0.01$ & $0.91(0.89-0.92)$ & $-0.13,0.06$ & $0.88(0.77-0.99)$ & $0.96,0.12$ & $2.62(2.07-3.32)$ & $<0.001$ \\
\hline $\mathrm{BMI}>30$ & $-0.08,0.01$ & $0.91(0.89-0.92)$ & $-0.37,0.05$ & $0.69(0.63-0.76)$ & $0.19,0.06$ & $1.21(1.07-1.37)$ & 0.003 \\
\hline Triglyceride $\geq 150$ & $-0.08,0.01$ & $0.91(0.89-0.92)$ & $-0.14,0.07$ & $0.87(0.76-0.99)$ & $-0.32,0.17$ & $0.72(0.52-1.00)$ & 0.053 \\
\hline \multicolumn{8}{|l|}{ Low HDL $(\mathrm{HDL}<50$ in women and } \\
\hline \multicolumn{8}{|l|}{$\mathrm{SBP} \geq 130$ or $\mathrm{DBP} \geq 85$ or on any } \\
\hline antihypertensive medications & $-0.08,0.01$ & $0.91(0.89-0.92)$ & $0.05,0.06$ & $1.05(0.93-1.19)$ & $0.11,0.08$ & $1.11(0.95-1.31)$ & 0.203 \\
\hline History of DM & $-0.08,0.01$ & $0.91(0.89-0.92)$ & $0.14,0.05$ & $1.15(1.06-1.26)$ & $0.40,0.06$ & $1.49(1.34-1.67)$ & $<0.001$ \\
\hline IDF & $-0.08,0.01$ & $0.91(0.89-0.92)$ & $-0.07,0.07$ & $0.93(0.81-1.06)$ & $1.24,0.12$ & $3.46(2.73-4.39)$ & $<0.001$ \\
\hline History of BMI $>30$ & $-0.08,0.01$ & $0.91(0.89-0.92)$ & $-0.37,0.05$ & $0.69(0.63-0.76)$ & $0.19,0.06$ & $1.21(1.07-1.37)$ & 0.003 \\
\hline \multicolumn{7}{|l|}{ Triglyceride $>150$ or taking either } & 0.424 \\
\hline \multicolumn{8}{|l|}{ Low HDL (HDL $<50$ in women and } \\
\hline HDL $<40$ in men) or any statins & $-0.08,0.01$ & $0.91(0.89-0.92)$ & $0.16,0.06$ & $1.17(1.03-1.33)$ & $0.48,0.12$ & $1.61(1.27-2.06)$ & $<0.001$ \\
\hline \multicolumn{8}{|l|}{$\mathrm{SBP}>130$ or $\mathrm{DBP}>85$ or on any } \\
\hline antihypertensive medications & $-0.08,0.01$ & $0.91(0.89-0.92)$ & $0.05,0.06$ & $1.05(0.93-1.19)$ & $0.11,0.08$ & $1.11(0.95-1.31)$ & 0.203 \\
\hline History of DM & $-0.08,0.01$ & $0.91(0.89-0.92)$ & $0.14,0.05$ & $1.15(1.06-1.26)$ & $0.40,0.06$ & $1.49(1.34-1.67)$ & $<0.001$ \\
\hline
\end{tabular}

Units for SBP and DBP are $\mathrm{mm} \mathrm{Hg}$ and for triglyceride and HDL they are $\mathrm{mg} / \mathrm{dl} . \mathrm{DM}=$ Diabetes mellitus.

0.06; $\mathrm{p}<0.001)$, SBP $\geq 140 \mathrm{~mm} \mathrm{Hg}$ or DBP $\geq 90 \mathrm{~mm} \mathrm{Hg}$ (PE, 0.18; SE, 0.15; $\mathrm{p}<0.001$ ) and higher BMI (PE, 0.19; $\mathrm{SE}, 0.06 ; \mathrm{p}=0.003)$. No statistically significant differences were found for triglyceride and HDL levels. The WHO criteria summary measure indicates that those with elder abuse were almost 6 times more likely to have metabolic syndrome [PE, 1.76; SE, 0.15; OR, 5.82 (4.34-7.79); $\mathrm{p}<$ $0.001]$. Although the degree of associations was different according to AHA and IDF definitions and specific items, those with elder abuse were over 2.5 times more likely [PE, 0.96; SE, 0.12; OR, $2.62(2.07-3.32) ; \mathrm{p}<0.001]$ by AHA criteria and almost 3.5 times more likely [PE, 1.24; SE, 0.12; OR, 3.46 (2.73-4.39); $\mathrm{p}>0.001$ ] by IDF criteria to have metabolic syndrome.

\section{Regression Analyses between Elder Abuse and \\ Different Metabolic Syndromes}

In table 4, we further considered an extensive list of potential confounders (models A-D) in the relationship between elder abuse and metabolic syndrome according to WHO, AHA and IDF definitions. In the fully adjusted model (model D), we considered a comprehensive list of sociodemographic, health status, psychosocial wellbeing and health behavioral factors. Although the degree of association was diminished compared with the models adjusting for only age and sex, elder abuse remained independently associated with metabolic syndromes according to WHO [OR, 3.95 (2.86-5.47)], AHA [OR, 2.03 (1.56-2.64)] and IDF [OR, 2.55 (1.97-3.29)] criteria.

\section{Interaction Term Analyses}

In table 5, we conducted interaction term analyses (elder abuse $\times$ sociodemographic factors) to examine potential moderating influences on metabolic syndromes. Although there were varying degrees of associations in the interaction terms with respect to the three metabolic syndrome definitions, age (WHO: PE, -0.06 ; SE, 0.02 ; p < 0.005 ), sex (IDF: PE, -0.51 ; SE, 0.22; $p<0.05$ ) and race (WHO: PE, -1.13 ; SE, 0.43 ; $\mathrm{p}<0.05$ ) could be potential moderating factors in the association between elder abuse and different definitions of metabolic syndromes; especially, there is a strong association among younger age groups, female gender and non-Hispanic white older adults. However, interaction term analyses suggest that health-related factors and psychosocial factors do not moderate the relationship between elder abuse and meta- 
Table 4. Regression analyses between elder abuse and metabolic syndrome definitions

\begin{tabular}{|c|c|c|c|c|}
\hline & $\begin{array}{l}\text { Model A, } \\
\text { OR (95\% CI) }\end{array}$ & $\begin{array}{l}\text { Model B, } \\
\text { OR (95\% CI) }\end{array}$ & $\begin{array}{l}\text { Model C, } \\
\text { OR (95\% CI) }\end{array}$ & $\begin{array}{l}\text { Model D, } \\
\text { OR (95\% CI) }\end{array}$ \\
\hline \multicolumn{5}{|l|}{ WHO } \\
\hline Age & $0.91(0.89-0.92)^{*}$ & $0.91(0.89-0.92)^{*}$ & $0.91(0.89-0.92)^{*}$ & $0.91(0.89-0.92)^{*}$ \\
\hline Sex & $1.19(0.96-1.46)$ & $1.15(0.92-1.43)$ & $1.12(0.89-1.40)$ & $1.19(0.95-1.49)$ \\
\hline Race & $1.31(1.02-1.69)^{*}$ & $1.33(1.02-1.73)^{*}$ & $1.34(1.02-1.75)^{*}$ & $1.19(0.91-1.58)$ \\
\hline Education & $0.95(0.91-0.98)^{*}$ & $0.95(0.92-0.99)^{*}$ & $0.96(0.92-0.99)^{*}$ & $0.96(0.92-0.99)^{*}$ \\
\hline Income & $0.87(0.83-0.92)^{*}$ & $0.90(0.86-0.95)^{*}$ & $0.91(0.86-0.95)^{*}$ & $0.91(0.86-0.96)^{*}$ \\
\hline Medical conditions & & $1.71(1.55-1.89)^{*}$ & $1.69(1.53-1.88)^{*}$ & $1.69(1.53-1.87)^{*}$ \\
\hline Cognitive function & & $1.11(0.95-1.29)$ & $1.13(0.96-1.33)^{*}$ & $1.15(0.98-1.36)$ \\
\hline Physical function & & $0.94(0.91-0.97)^{*}$ & $0.95(0.92-0.97)$ & $0.95(0.92-0.98)^{*}$ \\
\hline Depressive symptoms & & & $1.01(0.96-1.06)$ & $1.01(0.96-1.06)$ \\
\hline Social network & & & $0.99(0.98-1.02)$ & $1.00(0.98-1.02)$ \\
\hline Social engagement & & & $0.94(0.87-1.01)$ & $0.94(0.74-1.13)$ \\
\hline Smoking & & & & $0.92(0.74-1.13)$ \\
\hline Alcohol & & & & $0.63(0.48-0.82)$ \\
\hline Elder abuse & $4.23(3.12-5.73)^{*}$ & $3.76(2.73-5.18)^{*}$ & $3.79(2.75-5.24)^{*}$ & $3.95(2.86-5.47)^{*}$ \\
\hline \multicolumn{5}{|l|}{$A H A$} \\
\hline Age & $0.91(0.89-0.92)^{*}$ & $0.93(0.92-0.94)^{*}$ & $0.93(0.92-0.94)^{*}$ & $0.93(0.92-0.94)^{*}$ \\
\hline Sex & $0.96(0.84-1.09)$ & $0.93(0.81-1.07)$ & $0.91(0.79-1.05)$ & $0.96(0.83-1.11)$ \\
\hline Race & $0.85(0.73-0.98)^{*}$ & $0.83(0.71-0.96)^{*}$ & $0.85(0.73-0.99)^{*}$ & $0.75(0.64-0.89)^{*}$ \\
\hline Education & $0.97(0.95-0.99)^{*}$ & $0.97(0.95-0.99)^{*}$ & $0.97(0.95-0.99)^{*}$ & $0.98(0.95-0.99)^{*}$ \\
\hline Income & $0.92(0.89-0.95)^{*}$ & $0.94(0.91-0.97)^{*}$ & $0.94(0.91-0.98)^{*}$ & $0.95(0.92-0.98)^{*}$ \\
\hline Medical conditions & & $1.50(1.40-1.61)^{*}$ & $1.51(1.41-1.61)^{*}$ & $1.50(1.40-1.61)^{*}$ \\
\hline Cognitive function & & $1.14(1.04-1.27)^{*}$ & $1.16(1.05-1.29)^{*}$ & $1.19(1.07-1.32)^{*}$ \\
\hline Physical function & & $0.93(0.91-0.95)^{*}$ & $0.93(0.91-0.95)^{*}$ & $0.93(0.92-0.95)^{*}$ \\
\hline Depressive symptoms & & & $0.99(0.95-1.02)$ & $0.99(0.95-1.02)$ \\
\hline Social network & & & $1.01(1.00-1.03)^{*}$ & $1.02(1.00-1.03)^{*}$ \\
\hline Social engagement & & & $0.94(0.89-0.98)^{*}$ & $0.94(0.89-0.98)^{*}$ \\
\hline Smoking & & & & $0.96(0.85-1.10)$ \\
\hline Alcohol & & & & $0.63(0.54-0.73)^{*}$ \\
\hline Elder abuse & $2.30(1.81-2.94)^{*}$ & $1.90(1.47-2.46)^{*}$ & $1.92(1.48-2.49)^{*}$ & $2.03(1.56-2.64)^{*}$ \\
\hline \multicolumn{5}{|l|}{$I D F$} \\
\hline Age & $0.91(0.89-0.92)^{*}$ & $0.91(0.89-0.92)^{*}$ & $0.91(0.89-0.92)^{*}$ & $0.91(0.89-0.92)^{*}$ \\
\hline Sex & $0.99(0.87-1.14)$ & $1.00(0.86-1.16)$ & $0.99(0.85-1.15)$ & $1.03(0.89-1.20)$ \\
\hline Race & $1.16(0.99-1.36)$ & $1.19(1.02-1.41)^{*}$ & $1.24(1.05-1.46)^{*}$ & $1.18(0.99-1.40)$ \\
\hline Education & $0.96(0.94-0.98)^{*}$ & $0.95(0.93-0.97)^{*}$ & $0.95(0.93-0.98)^{*}$ & $0.95(0.93-0.98)^{*}$ \\
\hline Income & $0.94(0.91-0.97)^{*}$ & $0.96(0.93-0.99)^{*}$ & $0.96(0.93-0.99)^{*}$ & $0.96(0.93-0.99)^{*}$ \\
\hline Medical conditions & & $1.32(1.23-1.42)^{*}$ & $1.32(1.23-1.42)^{*}$ & $1.32(1.23-1.42)^{*}$ \\
\hline Cognitive function & & $1.33(1.19-1.48)^{*}$ & $1.35(1.20-1.51)^{*}$ & $1.37(1.22-1.53)^{*}$ \\
\hline Physical function & & $0.92(0.90-0.94)^{*}$ & $0.92(0.90-0.94)^{*}$ & $0.92(0.90-0.94)^{*}$ \\
\hline Depressive symptoms & & & $0.99(0.95-1.02)$ & $0.99(0.95-1.02)$ \\
\hline Social network & & & $1.01(0.99-1.02)$ & $1.01(0.99-1.02)$ \\
\hline Social engagement & & & $0.95(0.90-0.99)^{*}$ & $0.94(0.89-0.99)^{*}$ \\
\hline Smoking & & & & $0.86(0.74-0.98)^{*}$ \\
\hline Alcohol & & & & $0.85(0.72-1.00)$ \\
\hline Elder abuse & $2.79(2.19-3.57)^{*}$ & $2.46(1.91-3.18)^{*}$ & $2.48(1.92-3.20)^{*}$ & $2.55(1.97-3.29)^{*}$ \\
\hline
\end{tabular}

Cognitive function was assessed by the Mini-Mental State Examination, the East Boston Memory Test, the Symbol Digit Modality Test and the East Boston Memory Test delayed recall. ${ }^{*} \mathrm{p}<0.05$. 
Table 5. Interaction term analyses between elder abuse and various factors and metabolic syndrome definitions

\begin{tabular}{|c|c|c|c|}
\hline & $\begin{array}{l}\text { WHO, } \\
\text { PE, SE }\end{array}$ & $\begin{array}{l}\text { AHA, } \\
\text { PE, SE }\end{array}$ & $\begin{array}{l}\text { IDF, } \\
\text { PE, SE }\end{array}$ \\
\hline EA & $1.49,0.17^{* *}$ & $0.85,0.15^{* *}$ & $1.00,0.14^{* *}$ \\
\hline Age & $-0.08,0.01^{* *}$ & $-0.07,0.01^{* *}$ & $-0.09,0.01^{* *}$ \\
\hline $\mathrm{EA} \times$ age & $-0.06,0.02^{* *}$ & $-0.04,0.01^{*}$ & $-0.02,0.02$ \\
\hline EA & $1.53,0.19^{* *}$ & $0.81,0.15^{* *}$ & $1.08,0.15^{* *}$ \\
\hline Sex & $0.26,0.13^{*}$ & $-0.01,0.08$ & $0.09,0.08$ \\
\hline $\mathrm{EA} \times \operatorname{sex}$ & $-0.52,0.29$ & $-0.32,0.21$ & $-0.51,0.22^{*}$ \\
\hline EA & $2.40,0.41^{* *}$ & $1.19,0.31^{* *}$ & $1.42,0.31^{* *}$ \\
\hline Race & $0.27,0.15$ & $-0.25,0.01^{*}$ & $0.20,0.09^{*}$ \\
\hline $\mathrm{EA} \times$ race & $-1.13,0.42^{*}$ & $-0.54,0.31$ & $-0.54,0.31$ \\
\hline EA & $1.39,0.17^{* *}$ & $0.73,0.13^{* *}$ & $0.93,0.13^{* *}$ \\
\hline Education & $-0.05,0.02^{*}$ & $-0.03,0.01^{*}$ & $-0.05,0.01^{* *}$ \\
\hline EA $\times$ education & $0.04,0.04$ & $0.04,0.03$ & $-0.01,0.03$ \\
\hline EA & $1.35,0.17^{* *}$ & $0.75,0.14^{* *}$ & $0.94,0.13^{* *}$ \\
\hline Income & $-0.09,0.03^{* *}$ & $-0.06,0.02^{* *}$ & $-0.04,0.03^{*}$ \\
\hline $\mathrm{EA} \times$ income & $-0.03,0.06$ & $-0.82,0.77$ & $-0.37,0.85$ \\
\hline EA & $1.99,0.29 * *$ & $0.83,0.21^{* *}$ & $1.11,0.21^{* *}$ \\
\hline Medical conditions & $0.59,0.06^{* *}$ & $0.42,0.04^{* *}$ & $0.29,0.04^{* *}$ \\
\hline $\mathrm{EA} \times$ medical conditions & $-0.33,0.12$ & $-0.07,0.09$ & $-0.10,0.09$ \\
\hline EA & $1.38,0.17^{* *}$ & $0.71,0.13^{* *}$ & $0.93,0.13^{* *}$ \\
\hline Cognitive function & $0.10,0.09$ & $0.16,0.06^{*}$ & $0.32,0.06^{* *}$ \\
\hline EA $\times$ cognitive function & $0.17,0.18$ & $0.09,0.13$ & $-0.06,0.13$ \\
\hline EA & $1.29,0.27^{* *}$ & $0.79,0.21^{* *}$ & $0.91,0.21^{* *}$ \\
\hline Physical function & $-0.05,0.02^{* *}$ & $-0.07,0.01^{* *}$ & $-0.08,0.01^{* *}$ \\
\hline EA $\times$ physical function & $0.01,0.03$ & $-0.01,0.02$ & $0.01,0.02$ \\
\hline EA & $1.34,0.21^{* *}$ & $0.73,0.16^{* *}$ & $0.99,0.16^{* *}$ \\
\hline Depressive symptoms & $0.01,0.03$ & $-0.01,0.02$ & $-0.01,0.02$ \\
\hline EA $\times$ depressive symptoms & $0.01,0.05$ & $-0.01,0.04$ & $-0.03,0.04$ \\
\hline EA & $1.29,0.21^{* *}$ & $0.56,0.17^{* *}$ & $0.89,0.17^{* *}$ \\
\hline Social network & $-0.01,0.01$ & $0.01,0.01$ & $0.01,0.01$ \\
\hline EA $\times$ social network & $0.01,0.02$ & $0.03,0.02$ & $0.01,0.01$ \\
\hline EA & $1.38,0.21^{* *}$ & $0.78,0.17^{* *}$ & $0.94,0.17^{* *}$ \\
\hline Social engagement & $-0.07,0.04$ & $-0.06,0.03^{*}$ & $-0.06,0.03^{*}$ \\
\hline $\mathrm{EA} \times$ social engagement & $-0.01,0.08$ & $-0.04,0.06$ & $-0.01,0.06$ \\
\hline EA & $1.35,0.22^{* *}$ & $0.66,0.17^{* *}$ & $1.09,0.17^{* *}$ \\
\hline Smoking & $-0.09,0.12$ & $-0.05,0.07$ & $-0.12,0.08$ \\
\hline EA $\times$ smoking & $0.05,0.25$ & $0.09,0.19$ & $-0.28,0.19$ \\
\hline EA & $1.31,0.17^{* *}$ & $0.65,0.14^{* *}$ & $0.98,0.14^{* *}$ \\
\hline Alcohol & $-0.56,0.16^{* *}$ & $0.51,0.09^{* *}$ & $-0.13,0.09$ \\
\hline EA $\times$ alcohol & $0.42,0.33$ & $0.28,0.22$ & $-0.23,0.23$ \\
\hline
\end{tabular}

Model adjusted for age, sex, race, education, income, medical conditions, Mini-Mental State Examination, East Boston Memory Test, Symbol Digit Modality Test, East Boston Memory Test delayed recall, directly observed physical performance testing, depressive symptoms, social network, social engagement, smoking and alcohol use. EA = Elder abuse. ${ }^{*} \mathrm{p}<0.05 ;{ }^{* *} \mathrm{p}<0.005$. 
bolic syndromes. Lastly, we examined all of the above associations between confirmed elder abuse and metabolic syndromes and the results were all similar.

\section{Discussion}

In this population-based study of 4,586 adults aged 65 and older, we found that elder abuse was associated with an increased risk for metabolic syndromes regardless of the metabolic syndrome criteria used (WHO, AHA or IDF). In addition, younger older adults who had experienced elder abuse had a greater risk for metabolic syndrome. However, health-related and psychosocial factors did not seem to moderate the relationships between elder abuse and metabolic syndromes.

To our knowledge, this is the first study that has examined the association between elder abuse and metabolic syndromes, adding to the dearth of existing literature on violence and metabolic syndromes. Our study findings extend prior literature on metabolic consequences associated with child abuse and domestic violence. In a study by Midei et al. [26] using 342 participants from the Pittsburg site of the Study of Women's Health Across the Nation (SWAN), history of child abuse was associated with metabolic syndromes after controlling for age, race and menopausal status. Our findings are in contrast to those published by D'Ambrosio et al. [27] who found no statistically significant association between violence and metabolic syndromes among 220 patients with bipolar disorder. A review article by Kendall-Tackett [28] postulated that the relationships among inflammation, cardiovascular disease and metabolic syndrome were consequences of domestic violence, while depression, hostility and sleep disturbance were hypothesized as moderating factors leading to adverse health outcomes.

Our study further advances the prior literature by examining the association between elder abuse and metabolic syndromes in a representative community population of older adults within the context of a populationbased cohort study. First, we found that the prevalence of metabolic syndromes was higher among elder abuse victims, especially those who were younger elders, female and had a higher BMI. Second, we found that elder abuse was independently associated with an increased risk for metabolic syndromes regardless of the WHO, AHA or IDF criteria used, even after controlling for a comprehensive list of potential confounding factors. Third, we found that the association between elder abuse and metabolic syndromes may be moderated by sociodemographic characteristics, but not by health-related or psychosocial factors.

The temporal relations between elder abuse and metabolic syndromes need further investigation. We considered a series of potential confounders (socioeconomic characteristics, health habits, medical comorbidities, cognitive function, physical function and psychological and social wellbeing), but adjustments for these factors did not ameliorate the relationship between elder abuse and metabolic syndromes. Although prior research suggests that psychological distress influences both elder abuse and metabolic syndromes, our analyses suggest that psychological distress did not play a significant role in the relationship between elder abuse and metabolic syndromes. In addition, we found that participants with a younger age, women and those with a higher BMI were significantly more likely to have metabolic syndromes. It is possible that younger older adults and women experience a more severe form of elder abuse, thus exacerbating the relationship between elder abuse and metabolic syndromes. Future longitudinal studies are needed to explore these issues. It is also conceivable that those with elder abuse have other abnormalities in physiological or inflammatory biomarkers (IL-6, CRP, TNF- $\alpha$, etc.) that may mediate the relationships between elder abuse and metabolic syndromes. However, we do not have data on these measures and future studies are needed to elucidate the temporal relationships.

Our study also has a number of limitations that warrant consideration. First, elder abuse was identified by the social services agency and there is likely some degree of underreporting. Additional studies are needed that uniformly collect elder abuse measures in representative populations in order to validate the associations found in this study. Second, we had few participants in some of the specific subtypes of elder abuse, which limited our ability to quantify these relations. Larger studies may be needed to systematically examine the relationship between subtypes of elder abuse and metabolic syndromes. Third, we could not delineate the effect of inflammatory biomarkers in the relationship between elder abuse and metabolic syndromes and how these biomarkers may change the relationship between elder abuse and metabolic syndromes over time. Fourth, we did not have detailed clinical measures of severity of cardiovascular disease (e.g. congestive heart failure severity, ejection fraction, electrocardiogram findings or other measures of subclinical cardiovascular disease), so further work is needed to clarify this important issue in representative populations. 
This study has important practical implications. For health care professionals, screening for elder abuse should occur alongside consideration for cardiovascular disease and cardiometabolic conditions, especially among younger older adults, women and those with a higher BMI. At the same time, health professionals who care for patients with metabolic syndromes and other cardiovascular diseases should also consider asking older adults questions regarding family conflicts, elder abuse and home safety issues. It is important to understand not only the healthrelated contributing factors for cardiovascular disease, but also the social determinants that may contribute to metabolic syndromes.

Targeted education using cross-disciplinary and collaborative training strategies should be implemented to educate the public as well as social services and health care professionals on the implication of elder abuse on cardiovascular health. Given the recent literature highlighting the adverse health outcomes associated with elder abuse, it is important to consider broader social causes of morbidity and mortality through integrated curriculums. Although there is limited evidence yet on multidisciplinary team approaches to treat and prevent elder abuse, such approaches promise to greatly impact the field of elder abuse $[29,30]$. Findings from this study could help inform federal partners dealing with issues of elder abuse in policies and programs, specifically regarding adverse health outcomes associated with elder abuse. For instance, the Administration on Aging/Administration on Community Living is implementing the Elder Justice Act, the first federal policy dealing with issues of elder abuse. Our findings could contribute to the appropriation of the bill, Elder Justice Coordinating Council activities and reauthorizations of the Elder Justice Act in 2014.

\section{Conclusion}

We conclude that elder abuse is associated with an increased risk for metabolic syndromes regardless of the definitional criteria. However, the potential causal mechanisms and temporal relations between specific subtypes of elder abuse and metabolic syndromes require longitudinal investigation. Future intervention studies should be devised to reduce the frequency and severity of elder abuse in order to reduce its associated morbidities in representative populations.

\section{Acknowledgments}

Dr. Dong and Dr. Simon were supported by a National Institute on Aging grant (R01 AG042318, R01 MD006173, R34MH100443, R34MH100393, P20CA165588, R24MD001650 and RC4 AG039085), Paul B. Beeson Award in Aging, The Starr Foundation, American Federation for Aging Research, John A. Hartford Foundation and The Atlantic Philanthropies.

\section{Disclosure Statement}

The authors declare that they have no conflicts of interest.

\section{References}

1 Beach SR, Schulz R, Castle NG, Rosen J: Financial exploitation and psychological mistreatment among older adults: differences between African Americans and non-African Americans in a population-based survey. Gerontologist 2010;50:744-757.

-2 Acierno R, Hernandez MA, Amstadter AB, Resnick HS, Steve K, Muzzy W, et al: Prevalence and correlates of emotional, physical, sexual, and financial abuse and potential neglect in the United States: the National Elder Mistreatment Study. Am J Public Health 2010;100:292-297.

3 Dong X: Medical implications of elder abuse and neglect. Clin Geriatr Med 2005;21:293313.

4 Dong X, Simon M, Mendes de Leon C, Fulmer T, Beck T, Hebert L, et al: Elder self-neglect and abuse and mortality risk in a community-dwelling population. JAMA 2009;302:517-526.
5 Dong X, Simon MA, Beck T, McCann J, Farran $\mathrm{C}$, Laumann EO, et al: Elder abuse and mortality: the role of psychological and social wellbeing. Gerontology 2011;57:549-558.

-6 Martins D, Tareen N, Ogedegbe G, Pan D, Norris K: The relative risk of cardiovascular death among racial and ethnic minorities with metabolic syndrome: data from the NHANES-II mortality follow-up. J Natl Med Assoc 2008; 100:565-571.

7 Akbaraly TN, Kivimaki M, Ancelin ML, Barberger-Gateau P, Mura T, Tzourio C, et al: Metabolic syndrome, its components, and mortality in the elderly. J Clin Endocrinol Metab 2010;95:E327-E332.

>8 Forti P, Pirazzoli GL, Maltoni B, Bianchi G, Magalotti D, Muscari A, et al: Metabolic syndrome and all-cause mortality in older men and women. Eur J Clin Invest 2012;42:10001009.
9 Koehler C, Ott P, Benke I, Hanefeld M: Comparison of the prevalence of the metabolic syndrome by WHO, AHA/NHLBI, and IDF definitions in a German population with type 2 diabetes: the Diabetes in Germany (DIG) study. Horm Metab Res 2007;39:632635 .

10 Ma WY, Li HY, Hung CS, Lin MS, Chiu $\mathrm{FC}$, Lin $\mathrm{CH}$, et al: Metabolic syndrome defined by IDF and AHA/NHLBI correlates better to carotid intima-media thickness than that defined by NCEP ATP III and WHO. Diabetes Res Clin Pract 2009;85: 335-341.

11 Basol G, Barutcuoglu B, Cakir Y, Ozmen B, Parildar Z, Kose T, et al: Diagnosing metabolic syndrome in type 2 diabetic Turkish patients: comparison of AHA/NHLBI and IDF definitions. Bratisl Lek Listy 2011;112:253259. 
12 Bienias JL, Beckett LA, Bennett DA, Wilson RS, Evans DA: Design of the Chicago Health and Aging Project (CHAP). J Alzheimers Dis 2003;5:349-355.

13 Evans DA, Bennett DA, Wilson RS, Bienias JL, Morris MC, Scherr PA, et al: Incidence of Alzheimer disease in a biracial urban community: relation to apolipoprotein E allele status. Arch Neurol 2003;60:185-189.

14 Illinois Compiled Statutes Aging Elder Abuse and Neglect Act 320 ILCS 20. http://www.ilga. gov/legislation/ilcs/ilcs3.asp?ActID =1452\& ChapterID=31 (accessed June 30, 2007).

15 Cornoni-Huntley J, Brock DB, Ostfeld A, Taylor JO, Wallace RB: Established Populations for Epidemiological Studies of the Elderly Resource Data Book (Rep. No. NIH Publication No. 86-2443). Washington, US Department of Health and Human Services, 1986.

16 Dong X, Simon M, Beck T, Evans D: Decline in cognitive function and elder mistreatment: findings from the Chicago Health and Aging Project. Am J Geriatr Psychiatry 2014;22: 598-605.

17 Dong X, Simon M, Evans D: Decline in physical function and risk of elder abuse reported to social services in a community-dwelling population of older adults. J Am Geriatr Soc 2012;60:1922-1928.
18 Folstein MF, Folstein SE, McHugh PR: 'MiniMental State'. A practical method for grading the cognitive state of patients for the clinician. J Psychiatr Res 1975;12:189-198.

19 Albert M, Smith LA, Scherr PA, Taylor JO, Evans DA, Funkenstein HH: Use of brief cognitive tests to identify individuals in the community with clinically diagnosed Alzheimer's disease. Int J Neurosci 1991;57:167-178.

20 Smith A: Symbol Digit Modalities Test Manual - Revised. Los Angeles, Western Psychological, 1984.

21 Guralnik JM, Simonsick EM, Ferrucci L, Glynn RJ, Berkman LF, Blazer DG, et al: A short physical performance battery assessing lower extremity function: association with self-reported disability and prediction of mortality and nursing home admission. J Gerontol 1994;49:M85-M94.

22 Gill TM, Williams CS, Tinetti ME: Assessing risk for the onset of functional dependence among older adults: the role of physical performance. J Am Geriatr Soc 1995;43:603-609.

23 Kohout FJ, Berkman LF, Evans DA, CornoniHuntley J: Two shorter forms of the CES-D (Center for Epidemiological Studies Depression) depression symptoms index. J Aging Health 1993;5:179-193.
24 Radloff L: The CES-D scale: a self-report depression scale for research in the general population. Appl Psychol Measures 1977;1:385401.

25 SAS Institute Inc: SAS OnlineDoc, Version 9.1.3. Cary, SAS Institute Inc, 2004

26 Midei AJ, Matthews KA, Chang YF, Bromberger JT: Childhood physical abuse is associated with incident metabolic syndrome in mid-life women. Health Psychol 2013;32: 121-127.

27 D’Ambrosio V, Salvi V, Bogetto F, Maina G: Serum lipids, metabolic syndrome and lifetime suicide attempts in patients with bipolar disorder. Prog Neuropsychopharmacol Biol Psychiatry 2012;37:136-140.

28 Kendall-Tackett KA: Inflammation, cardiovascular disease, and metabolic syndrome as sequelae of violence against women: the role of depression, hostility, and sleep disturbance. Trauma Violence Abuse 2007;8:117126

29 Dong X, Simon MA: Enhancing national policy and programs to address elder abuse. JAMA 2011;305:2460-2461.

30 Mosqueda L, Dong X: Elder abuse and selfneglect: 'I don't care anything about going to the doctor, to be honest ...'. JAMA 2011;306: 532-540. 